\title{
Antimicrobial and antioxidant activity of kaempferol rhamnoside derivatives from Bryophyllum pinnatum
}

Simplice Joel Ndendoung Tatsimo ${ }^{\text {* }}$, Jean de Dieu Tamokou², Léopold Havyarimana ${ }^{3}$, Dezső Csupor ${ }^{4}$, Peter Forgo ${ }^{4}$, Judit Hohmann ${ }^{4}$, Jules-Roger Kuiate ${ }^{2}$ and Pierre Tane ${ }^{5}$

\begin{abstract}
Background: Bryophyllum pinnatum (Lank.) Oken (Crassulaceae) is a perennial succulent herb widely used in traditional medicine to treat many ailments. Its wide range of uses in folk medicine justifies its being called "life plant" or "resurrection plant", prompting researchers' interest. We describe here the isolation and structure elucidation of antimicrobial and/or antioxidant components from the EtOAc extract of B. pinnatum.

Results: The methanol extract displayed both antimicrobial activities with minimum inhibitory concentration (MIC) values ranging from 32 to $512 \mu \mathrm{g} / \mathrm{ml}$ and antioxidant property with an $\mathrm{IC}_{50}$ value of $52.48 \mu \mathrm{g} / \mathrm{ml}$. Its partition enhanced the antimicrobial activity in EtOAc extract $(\mathrm{MIC}=16-128 \mu \mathrm{g} / \mathrm{ml})$ and reduced it in hexane extract $(\mathrm{MIC}=$ 256-1024 $\mu \mathrm{g} / \mathrm{ml})$. In addition, this process reduced the antioxidant activity in EtOAc and hexane extracts with $\mathrm{IC}_{50}$ values of 78.11 and $90.04 \mathrm{\mu g} / \mathrm{ml}$ respectively. Fractionation of EtOAc extract gave seven kaempferol rhamnosides, including; kaempferitrin (1), kaempferol 3-O- $\alpha$-L-(2-acetyl)rhamnopyranoside-7-O- $\alpha$-L-rhamnopyranoside (2), kaempferol 3-O- $\alpha$-L-(3-acetyl)rhamnopyranoside-7-O- $\alpha$-L-rhamnopyranoside (3), kaempferol 3-O- $\alpha$-L-(4-acetyl) rhamnopyranoside-7-O- $\alpha$-L-rhamnopyranoside (4), kaempferol 3-O- $\alpha$-D- glucopyranoside-7-O- $\alpha-L-$ rhamnopyranoside (5), afzelin (6) and $\boldsymbol{\alpha}$-rhamnoisorobin (7). All these compounds, except $\mathbf{6}$ were isolated from this plant for the first time. Compound $\mathbf{7}$ was the most active, with MIC values ranging from 1 to $2 \mu \mathrm{g} / \mathrm{ml}$ and its antioxidant activity $\left(I C_{50}=0.71 \mu \mathrm{g} / \mathrm{ml}\right)$ was higher than that of the reference drug $\left(I C_{50}=0.96 \mu \mathrm{g} / \mathrm{ml}\right)$.

Conclusion: These findings demonstrate that Bryophyllum pinnatum and some of its isolated compounds have interesting antimicrobial and antioxidant properties, and therefore confirming the traditional use of B. pinnatum in the treatment of infectious and free radical damages.
\end{abstract}

Keywords: Bryophyllum pinnatum, Crassulaceae, Kaempferol rhamnosides, Antimicrobial, Antioxidant, Minimum inhibitory concentration

\section{Background}

Bryophyllum pinnatum (Lank.) Oken, syn. B. calucinum or Kalanchoe pinnata (Crassulaceae) is a perennial succulent herb which grows in Africa and Asia [1]. An ethnobotanical survey of plants used in the treatment of infectious diseases in Mbouda subdivision (Cameroon) indicated that $B$. pinnatum was one of the most used medicinal plants in the area. Therefore information

\footnotetext{
* Correspondence: jtatsimo@yahoo.com

'Department of Chemistry, Higher Teachers' Training College, University of

Maroua, P.O. Box 55, Maroua, Cameroon

Full list of author information is available at the end of the article
}

collected directly from traditional healers and herbal sellers in this area indicated that, leaves or the whole plant are used as analgesic and to treat blennorrhoea, syphilis, jaundice, candidiasis, dysmenorrhoea, external ulcers, burns and convulsions. B. pinnatum is also used elsewhere for treatment of ear infections, cough and dysentery [2]. This wide range of traditional uses justifies its being called "life plant", "resurrection plant" or "goodluck" [3,4]. Previous phytochemical studies revealed the presence of terpenoids [1], cytotoxic bufadienolides [5] and antileishmanial flavonoids [6] in this plant. In addition, $60 \%$ methanolic extract of leaves of $B$. 
pinnatum have shown antimicrobial activity [2], while water extracts have shown anti-ulcer, antinociceptive, anti-inflammatory, antidiabetic, neurosedative and muscle relaxant activities $[3,4,7]$, and ethanolic extract have exhibited hepatoprotective activity [8]. In the course of our search for bioactive components from Cameroonian medicinal plants, phytochemical and biological investigations of B. pinnatum were carried out. We describe here the isolation and structure elucidation, antimicrobial and antioxidant properties of seven kaempferol rhamnosides (1-7) from B. pinnatum which may account for some of the ethnomedicinal uses of leaves or the whole plant.

\section{Results}

\section{Chemical analysis}

The whole plant of $B$ pinnatum was dried between 36$38^{\circ} \mathrm{C}$ during two weeks. This raw material $(1.50 \mathrm{Kg})$ was extracted with $\mathrm{MeOH}$ and the $\mathrm{MeOH}$ extract was partitioned with hexane and ethyl acetate. The resulting extracts underwent antimicrobial (antibacterial and antifungal) and antioxidant assays revealing MICs values from $16-1024 \mu \mathrm{g} / \mathrm{ml}$ and $\mathrm{IC}_{50}$ values from $52.48-90.04$ $\mu \mathrm{g} / \mathrm{ml}$. The antimicrobial activity was found to be more concentrated in EtOAc extract and diluted in hexane extract. The EtOAc extract was then subjected to column chromatography to yield seven kaempferol derivatives: kaempferitrin (435.10 mg) (1) [9], kaempferol 3-O$\alpha$-L-(2-acetyl)rhamnopyranoside-7-O- $\alpha$-L-rhamnopyranoside (10.10 mg) (2) [10], kaempferol 3-O- $\alpha-\mathrm{L}-(3-$
acetyl)rhamnopyranoside-7-O- $\alpha$-L-rhamnopyranoside (38.40 mg) (3) [10], kaempferol 3-O- $\alpha$-L-(4-acetyl)rhamnopyranoside-7-O- $\alpha$-L-rhamnopyranoside $(25.10 \mathrm{mg})(\mathbf{4})$ [11], kaempferol 3-O- $\alpha$-D- glucopyranoside-7-O- $\alpha-\mathrm{L}-$ rhamnopyranoside (40,90 mg) (5) [12], afzelin (34.60 $\mathrm{mg}$ ) (6) [9] and $\alpha$-rhamnoisorobin $(5.0 \mathrm{mg}$ ) (7) [9] (Figure 1). These compounds except afzelin (6) were isolated for the first time in this species.

\section{Antimicrobial activity}

The $\mathrm{MeOH}, \mathrm{EtOAc}$ and hexane extracts as well as isolated compounds were tested for their antimicrobial activity and the results obtained are presented in Table 1. The crude extracts have shown both antibacterial and antifungal activities, on the set of germs tested with MIC values ranging from 16 to $1024 \mu \mathrm{g} / \mathrm{ml}$. The EtOAc extract was more active $(\mathrm{MIC}=16-128 \mu \mathrm{g} / \mathrm{ml}$ ) than the $\mathrm{MeOH}$ extract $(\mathrm{MIC}=32-512 \mu \mathrm{g} / \mathrm{ml})$ and the hexane extract $(\mathrm{MIC}=128-1024 \mu \mathrm{g} / \mathrm{ml})$, meaning that the active principles might be more concentrated in the EtOAc extract. Compound 7 isolated from the EtOAc extract was more active $(\mathrm{MIC}=1-2 \mu \mathrm{g} / \mathrm{ml})$ than all the other tested compounds. This is followed in decreasing order by compounds 5, 6, 1, 3 and 4 . The antimicrobial activity of compound 7 was in some cases equal to those of the positive controls (ciprofloxacin and nystatin). Nevertheless, the antibacterial activity of this compound (MIC $=1 \mu \mathrm{g} / \mathrm{ml}$ ) was higher than that of the positive control ciprofloxacin ( $\mathrm{MIC}=2 \mu \mathrm{g} / \mathrm{ml}$ ) against Pseudomonas aeruginosa.<smiles>[R]Oc1cc(O)c2c(=O)c(O[R])c(-c3ccc(O)cc3)oc2c1</smiles>

$\mathrm{R}_{1}=$ Rha, $\mathrm{R}_{2}=$ Rha: kaempferitrin, $\mathbf{1}$

$\mathrm{R}_{1}=\mathrm{Rha}^{2} \mathrm{OAc}, \mathrm{R}_{2}=$ Rha: kaempferol 3-O- $\alpha$-L-(2-acetyl)rhamnopyranoside-7- $O$ - $\alpha$-L-rhamnopyranoside, 2

$\mathrm{R}_{1}=\mathrm{Rha}^{3} \mathrm{OAc}, \mathrm{R}_{2}=\mathrm{Rha}$ : kaempferol 3-O- $\alpha$-L-(3-acetyl)rhamnopyranoside-7-O- $\alpha$-L-rhamnopyranoside, 3

$\mathrm{R}_{1}=$ Rha- ${ }^{4} \mathrm{OAc}, \mathrm{R}_{2}=$ Rha: kaempferol 3-O- $\alpha$-L-(4-acetyl)rhamnopyranoside-7-O- $\alpha$-L-rhamnopyranoside, 4

$\mathrm{R}_{1}=$ Glc, $\mathrm{R}_{2}=$ Rha: kaempferol 3-O- $\alpha$-D- glucopyranoside-7- $O$ - $\alpha$-L-rhamnopyranoside, 5

$\mathrm{R}_{1}=\mathrm{Rha}, \mathrm{R}_{2}=\mathrm{H}$ : afzelin, 6

$\mathrm{R}_{1}=\mathrm{H}, \mathrm{R}_{2}=$ Rha: $\alpha$-rhamnoisorobin, 7

Figure 1 Chemical structures of compounds isolated from B. pinnatum. 
Table 1 Antimicrobial activity (in $\mu \mathrm{g} / \mathrm{ml}$ ) of crude extracts of B. pinnatu $m$ and isolates from EtOAc extract

\begin{tabular}{|c|c|c|c|c|c|c|c|}
\hline $\begin{array}{l}\text { Test samples (extracts and } \\
\text { isolates 1-7) }\end{array}$ & $\begin{array}{l}\text { Inhibition } \\
\text { parameters }\end{array}$ & $\begin{array}{l}\text { Staphylococcus } \\
\text { aureus }\end{array}$ & $\begin{array}{l}\text { Pseudomonas } \\
\text { aeruginosa }\end{array}$ & $\begin{array}{l}\text { Salmonella } \\
\text { typhi }\end{array}$ & $\begin{array}{l}\text { Candida } \\
\text { albicans }\end{array}$ & $\begin{array}{l}\text { Candida } \\
\text { parapsilosis }\end{array}$ & $\begin{array}{l}\text { Cryptococcus } \\
\text { neoformans }\end{array}$ \\
\hline \multirow[t]{3}{*}{$\mathrm{MeOH}$ extract } & MIC & 256 & 512 & 64 & 64 & 32 & 32 \\
\hline & $\overline{M M C}$ & 256 & 512 & 128 & 64 & 32 & 64 \\
\hline & $\overline{\mathrm{MMC} / \mathrm{MIC}}$ & 1 & 1 & 2 & 1 & 1 & 2 \\
\hline \multirow[t]{3}{*}{ EtOAc extract } & MIC & 64 & 128 & 16 & 32 & 16 & 16 \\
\hline & $\overline{M M C}$ & 64 & 256 & 16 & 32 & 32 & 16 \\
\hline & $\overline{\mathrm{MMC} / \mathrm{MIC}}$ & 1 & 2 & 1 & 1 & 2 & 1 \\
\hline \multirow[t]{3}{*}{$n$-hexane extract } & MIC & 512 & 1024 & 256 & 256 & 128 & 1024 \\
\hline & $\mathrm{MMC}$ & 512 & 1024 & 256 & 256 & 128 & 1024 \\
\hline & MMC/MIC & 1 & 1 & 1 & 1 & 1 & 1 \\
\hline \multirow[t]{3}{*}{1} & MIC & 32 & 32 & 32 & 32 & 16 & 16 \\
\hline & $\mathrm{MMC}$ & 32 & 64 & 32 & 64 & 16 & 16 \\
\hline & $\overline{\mathrm{MMC} / \mathrm{MIC}}$ & 1 & 2 & 1 & 2 & 1 & 1 \\
\hline \multirow[t]{3}{*}{4} & MIC & 64 & 128 & 32 & 64 & 32 & 32 \\
\hline & MMC & 64 & 128 & 32 & 128 & 32 & 32 \\
\hline & $\mathrm{MMC} / \mathrm{MIC}$ & 1 & 1 & 1 & 2 & 1 & 1 \\
\hline \multirow[t]{3}{*}{6} & MIC & 8 & 16 & 2 & 16 & 4 & 4 \\
\hline & $\mathrm{MMC}$ & 8 & 16 & 2 & 32 & 4 & 4 \\
\hline & $\mathrm{MMC} / \mathrm{MIC}$ & 1 & 1 & 1 & 2 & 1 & 1 \\
\hline \multirow[t]{3}{*}{5} & MIC & 4 & 4 & 1 & 8 & 2 & 2 \\
\hline & $\overline{M M C}$ & 8 & 4 & 2 & 8 & 2 & 4 \\
\hline & $\mathrm{MMC} / \mathrm{MIC}$ & 2 & 1 & 2 & 1 & 1 & 2 \\
\hline \multirow[t]{3}{*}{7} & MIC & 2 & 1 & 1 & 1 & 2 & 2 \\
\hline & MMC & 2 & 2 & 1 & 1 & 2 & 2 \\
\hline & $\overline{\mathrm{MMC} / \mathrm{MIC}}$ & 1 & 2 & 1 & 1 & 1 & 1 \\
\hline \multirow[t]{3}{*}{3} & MIC & 256 & 128 & 64 & 32 & 16 & 16 \\
\hline & MMC & 256 & 128 & 64 & 32 & 32 & 16 \\
\hline & $\mathrm{MMC} / \mathrm{MIC}$ & 1 & 1 & 1 & 1 & 2 & 1 \\
\hline \multirow[t]{3}{*}{ Ciprofloxacin } & MIC & 2 & 2 & 0.5 & 1 & I & I \\
\hline & $\mathrm{MMC}$ & 2 & 2 & 1 & / & I & I \\
\hline & $\mathrm{MMC} / \mathrm{MIC}$ & 1 & 1 & 2 & I & 1 & I \\
\hline \multirow[t]{3}{*}{ Nystatin } & MIC & I & I & 1 & 2 & 1 & 0.5 \\
\hline & $\overline{\mathrm{MMC}}$ & 1 & 1 & 1 & 2 & 1 & 0.5 \\
\hline & $\mathrm{MMC} / \mathrm{MIC}$ & I & 1 & I & 1 & 1 & 1 \\
\hline
\end{tabular}

I: not determined

\section{Antioxidant activity}

The results of the antioxidant activities of the $\mathrm{MeOH}$, EtOAc and hexane extracts as well as their isolated compounds are presented in Table 2. It appeared that the $\mathrm{MeOH}$ extract $\left(\mathrm{IC}_{50}=52.48 \mu \mathrm{g} / \mathrm{ml}\right)$ was more active than the EtOAc extract $\left(\mathrm{IC}_{50}=78.11 \mu \mathrm{g} / \mathrm{ml}\right)$ and hexane extract $\left(\mathrm{IC}_{50}=90.04 \mu \mathrm{g} / \mathrm{ml}\right)$. The antioxidant activity of compound $7\left(\mathrm{IC}_{50}=0.71 \mu \mathrm{g} / \mathrm{ml}\right)$ was higher than that of the reference drug $\left(\mathrm{IC}_{50}=0.96 \mu \mathrm{g} / \mathrm{ml}\right)$. No biological test was done with compound $\mathbf{2}$ since it was obtained as a mixture with compound $\mathbf{3}$.

\section{Discussion}

The findings of the present study showed differences between the antimicrobial activities of crude $\mathrm{MeOH}$ extract and extracts from partition. This suggests that $B$. pinnatum contains several antifungal and antibacterial principles with different polarities as shown by the phytochemical study. The partition of the $\mathrm{MeOH}$ extract enhanced its antimicrobial activity in EtOAc fraction, and reduced that of hexane fraction. This indicates that the active principles might be more concentrated in EtOAc fraction and more diluted in hexane fraction. All 
Table 2 Inhibition concentrations of the test samples scavenging $50 \%$ of DPPH radical $\left(\mathrm{IC}_{\mathbf{5 0}}\right)$

\begin{tabular}{ll}
\hline $\begin{array}{l}\text { Test samples (extracts and isolates } \mathbf{1 - 7} \text { from EtOAc } \\
\text { extract) }\end{array}$ & $\mathbf{I C}_{\mathbf{5 0}}(\boldsymbol{\mu} \mathbf{g} / \mathbf{m l})$ \\
\hline MeOH extract & $52.48 \pm 0.19^{\mathrm{a}}$ \\
\hline EtOAc extract & $78.11 \pm 0.61^{\mathrm{b}}$ \\
\hline$n$-hexane extract & $90.04 \pm 1.26^{\mathrm{c}}$ \\
\hline $\mathbf{1}$ & $8.73 \pm 0.51^{\mathrm{d}}$ \\
\hline $\mathbf{4}$ & $273.81 \pm 0.43^{\mathrm{e}}$ \\
\hline $\mathbf{3}$ & $487.99 \pm 0.81^{\mathrm{f}}$ \\
\hline $\mathbf{6}$ & $6.44 \pm 0.74^{\mathrm{g}}$ \\
\hline $\mathbf{5}$ & $2.28 \pm 0.12^{\mathrm{h}}$ \\
\hline $\mathbf{7}$ & $0.71 \pm 0.09^{\mathrm{j}}$ \\
\hline Vitamin C & $0.96 \pm 0.14^{\mathrm{j}}$ \\
\hline
\end{tabular}

Values are expressed as mean \pm SD. In the same column, values affected by the different superscript letters (a-j) are significantly different $p<0.05$.

the isolated compounds showed antimicrobial activities on at least one microorganism. Such a finding supports the traditional use of this plant in the treatment of infectious diseases. The result of the antimicrobial activity of $\mathrm{MeOH}$ extract from the whole plant of B. Pinnatum corroborates that of Akinpelu [2].

The antimicrobial activities varied with the bacterial and fungal species. These variations may be due to genetic differences between the microorganisms. A keen look at the results of MIC and minimum microbicidal concentration (MMC) (Table 1), showed that the MIC values obtained are in most cases equal to the MMC values on the corresponding (sensitive) microorganisms, confirming the microbicidal effects of the tried samples [13]. This is interesting in view of the perspective of developing new antibacterial drugs from natural products.

The antimicrobial activity was more concentrated in EtOAc fraction. In contrast, the antioxidant activity is more concentrated in $\mathrm{MeOH}$ extract. This indicates that partition of the crude extract did not enhance the antioxidant activity of its fractions. Flavonoid compounds such as compounds 1-7 are known to be potential antioxidant due to their ability to scavenge free radicals and active oxygen species such as singlet oxygen, superoxide anion radical and hydroxyl radicals $[14,15]$. The antimicrobial activity of flavonoids (compounds 1-7) might be due to their ability to complex with bacteria cell wall and therefore, inhibiting the microbial growth [16]. The presence of these compounds could explain the antioxidant activity found in the crude extract.

Compounds 1, 3-7 displayed both antibacterial and antifungal activities. However, this is the first report concerning the antimicrobial and antioxidant activities of these compounds.

The overall results of this study can be considered as very promising in the perspective of new drugs discovery from plant sources, when considering the medical importance of tested microorganisms. Staphylococcus aureus is a major cause of community and hospital-associated infection with an estimated mortality of around 7-10\% [17]. About $77 \%$ of immune-deficient patients' death is attributed to microscopic fungi, such as Candida species and Cryptococcus neoformans [18]. Also, Candida albicans has been reported to account for $50-70 \%$ cases of invasive candidiasis [19]. Alarmingly, the incidence of nosocomial candidemia has risen sharply in the last decade [20]. All this has resulted in severe consequences including increased cost of medicines and mortality of patients. Typhoid fever caused by Salmonella typhi continues to be a serious public health problem in developing countries in general and in Sub-Saharan Africa in particular [17]. Generally, these pathogens were found to be sensitive to extracts and isolated compounds.

\section{Conclusion}

These findings demonstrated that methanol and ethyl acetate extracts of B. pinnatum and the isolated compounds exhibited interesting antimicrobial and antioxidant properties, justifying the traditional uses of the plant in the treatment of infectious diseases and free radical damages. However, further pharmacological and toxicological studies need to be done in order to confirm or infirm this hypothesis.

\section{Methods}

\section{Plant material}

The whole plant of $B$. pinnatum was collected in Mbouda subdivision, West region of Cameroon in August 2009. It was identified by Mr. Nana at the National Herbarium, Yaoundé where a voucher specimen 33394 HNC describing the plant is deposited.

\section{Extraction and isolation}

Dried and ground whole plant of B. pinnatum [1] $(1.50 \mathrm{Kg})$ was extracted by percolation with methanol $(10 \mathrm{~L})$ at room temperature. Filtration and evaporation of solvent under reduced pressure gave a brown residue $(148 \mathrm{~g})$. This extract was successively partitioned with $n$-hexane and ethyl acetate to yield 38.03 and $34.03 \mathrm{~g}$ of extracts respectively [21]. All extracts were kept in the refrigerator at around $4^{\circ} \mathrm{C}$.

The EtOAc extract (34.03 g) was subjected to silica gel column chromatography $(6 \times 30 \mathrm{~cm}, 300 \mathrm{~g})$ eluted with a gradient system of hexane- $\mathrm{EtOAc}-\mathrm{MeOH}$ gradients. 182 fractions of $200 \mathrm{~mL}$ each were collected and combined according to TLC profile into nine main fractions: A (fractions 1-45), B (fractions 46-70), C (fractions 7192), D (fractions 93-109), E (fractions 110-129), F (fractions 130-140), G (fractions 141-154), H (fractions 155170), I (fractions 171-182). G (8.91 g) was loaded on a silica gel column eluted with $\mathrm{CH}_{2} \mathrm{Cl}_{2}-\mathrm{MeOH}$ gradients 
and 200 fractions of $13 \mathrm{ml}$ each were collected. Subfractions 114-140 obtained with $\mathrm{CH}_{2} \mathrm{Cl}_{2}-\mathrm{MeOH}$ (87.5-12.5, $200 \mathrm{~mL} ; 85-15,200 \mathrm{~mL}$ ) were again subjected to silica gel column chromatography eluted with a gradient system of EtOAc- MeOH- $\mathrm{H}_{2} \mathrm{O}$ to yield 50 fractions of 13 $\mathrm{mL}$ each. Subfractions 8-11 obtained with EtOAc$\mathrm{MeOH}-\mathrm{H}_{2} \mathrm{O}$ (98-02-0.1) were purified on a sephadex LH-20 column eluted with $\mathrm{MeOH}$ to give afzelin (6) as yellow crystal; and $\alpha$-rhamnoisorobin (7) as amorphous yellowish pate. Subfractions 17-32 obtained with EtOAc$\mathrm{MeOH}-\mathrm{H}_{2} \mathrm{O}$ (98-02-0.1 and 96-04-0.1) were loaded on vaccum $\mathrm{RP}-18$ column eluted with $\mathrm{H}_{2} \mathrm{O}-\mathrm{MeOH}$ gradients (60-40 to 0-100) and fractions obtained were loaded on preparative RP-TLC to yield kaempferol 3-O$\alpha$-L-(3-acetyl)rhamnopyranoside-7-O- $\alpha$-L-rhamnopyranoside (3), kaempferol 3-O- $\alpha$-L-(4-acetyl)rhamnopyranoside-7-O- $\alpha$-L-rhamnopyranoside (4) and a mixture of kaempferol 3-O- $\alpha$-L-(2-acetyl)rhamnopyranoside-7-O- $\alpha$ L-rhamnopyranoside (2) and compound 3. Subfractions 141-155 from $\mathrm{G}$, obtained with $\mathrm{CH}_{2} \mathrm{Cl}_{2}$ - $\mathrm{MeOH}$ (81.5$17.5 ; 200 \mathrm{~mL}$ ) were purified on a sephadex LH-20 column eluted with $\mathrm{MeOH}$ to yield yellow crystal of kaempferitrin (1). I (821 mg) was loaded on vaccum RPcolumn eluted with $\mathrm{H}_{2} \mathrm{O}-\mathrm{MeOH}$ gradients (60-40 to 0100) and 67 fractions of $15 \mathrm{~mL}$ each were collected. Subfractions 30-45 obtained with $\mathrm{H}_{2} \mathrm{O}-\mathrm{MeOH}$ (85-15) were again subjected to $\mathrm{RP}$-column eluted with $\mathrm{H}_{2} \mathrm{O}$ $\mathrm{MeOH}$ (60-0 to 40-60) and fractions were purified on $\mathrm{MeOH}$ sephadex column and an isocratic $\mathrm{H}_{2} \mathrm{O}-\mathrm{MeOH}$ (80-20) RP-column to yield 3-O- $\alpha$-D-glucopyranoside-7$O-\alpha$-L-rhamnopyranoside (5). The chemical structures of the isolated compounds are shown in Figure 1.

\section{General procedure}

NMR spectra were measured on Bruker Avance DRX 500 and Brucker Ultrashield Plus 600 spectrometers at 500 and $600 \mathrm{MHz}$ for ${ }^{1} \mathrm{H}$, and 125 and $150 \mathrm{MHz}$ for ${ }^{13} \mathrm{C}$ NMR, with TMS as internal standard; chemical shifts are given in $\delta$ values (ppm). MS analyses were performed using a QTOF Premier (Waters, Milford, MA) equipped with a nanoelectrospray ionization source. The instrument was operated in positive ion mode, performing fullscan analysis over the $m / z$ range $50-1990$ at 1 spectra/s. Column chromatography was run on Merck silica gel 60 (0.063-0.200 mm), Lichoprep RP-18 (40-63 $\mu \mathrm{m})$ and Sephadex LH-20 while TLC was carried out on silica gel $\mathrm{GF}_{254}$ pre-coated plates with detection accomplished by visualizing with a UV lamp at 254 and $365 \mathrm{~nm}$, followed by spraying with vanillin and then heating at $100^{\circ} \mathrm{C}$.

\section{Biological tests}

\section{Antimicrobial activity}

Microorganisms The microorganisms used in this study consisted of three bacteria (Staphylococcus aureus
ATCC25922, Pseudomonas aeruginosa ATCC27853, Salmonella typhi ATCC6539) and two Candida species (Candida albicans ATCC9002 and Candida parapsilosis ATCC22019), all of which are reference strains obtained from the American Type Culture Collection. Also, included was one strain of Cryptococcus neoformans IP95026 obtained from the Pasteur Institute (IP, ParisFrance). The bacterial and yeast strains were grown at $35^{\circ} \mathrm{C}$ and maintained on nutrient agar (NA, Conda, Madrid, Spain) and Sabouraud Dextrose Agar (SDA, Conda) slants, respectively.

Determination of Minimum Inhibitory Concentration (MIC) and Minimum Microbicidal Concentration (MMC) MICs were determined by broth micro dilution method as described by Nyaa et al. in 2009 with slight modifications [22]. The test samples were first of all dissolved in dimethylsulfoxide (DMSO). The solution obtained was then added to Mueller Hinton Broth (MHB) for bacteria or Sabouraud Dextrose Broth (SDB) for yeasts to give a final concentration of $2048 \mu \mathrm{g} / \mathrm{ml}$. This was serially diluted two fold to obtain concentration ranges of 0.50 to $2048 \mu \mathrm{g} / \mathrm{ml}$. Each concentration $(100 \mu \mathrm{l})$ was added in each well (96-wells microplate) containing $95 \mu \mathrm{l}$ of $\mathrm{MHB}$ or SDB and $5 \mu \mathrm{l}$ of inoculum for final concentrations varying from 0.25 to $1024 \mu \mathrm{g} /$ $\mathrm{ml}$. The inoculum was standardized at $1.50 \times 10^{6} \mathrm{CFU} /$ $\mathrm{ml}$ by adjusting the optical density to 0.10 at $600 \mathrm{~nm}$ JENWAY $6105 \mathrm{UV} / \mathrm{Vis}$ spectrophotometer. The final concentration of DMSO in each well was less than $1 \%$ (preliminary analyses with $1 \%(\mathrm{v} / \mathrm{v})$ DMSO do not inhibit the growth of the test organisms). The negative control well consisted of $195 \mu \mathrm{l}$ of appropriate medium (MHB for bacteria and SDB for yeasts) and $5 \mu$ l of the standard inoculum. The plates were covered with the sterile lid, then agitated to mix the contents of the wells using a plate shaker and incubated at $35^{\circ} \mathrm{C}$ for $24 \mathrm{~h}$ (for bacteria) or for $48 \mathrm{~h}$ (for yeasts). The assay was repeated thrice. The MICs of samples were determined by adding $50 \mu \mathrm{l}$ of a $0.2 \mathrm{mg} / \mathrm{ml}$-iodonitrotetrazolium violet solution followed by incubation at $35^{\circ} \mathrm{C}$ for $30 \mathrm{~min}$. Viable micro-organisms reduced the yellow dye to a pink color. MICs were defined as the lowest sample concentrations that prevented this change in color indicating a complete inhibition of microbial growth.

For the determination of MMCs, a portion of liquid (5 $\mu \mathrm{l})$ from each well that showed no growth of microorganism was placed on Mueller Hinton Agar or Sabouraud Dextrose Agar and incubated at $35^{\circ} \mathrm{C}$ for $24 \mathrm{~h}$ (for bacteria) or $35^{\circ} \mathrm{C}$ for $48 \mathrm{~h}$ (for yeasts). The lowest concentrations that yielded no growth after this sub-culturing were taken as the MMCs [22]. Ciprofloxacin (Sigma-Aldrich, Steinheim, Germany) and nystatin (Merck, Darmstadt, Germany) for bacteria and yeasts, respectively, were used as positive controls. 


\section{Antioxidant assay}

The antioxidant activities of methanol, EtOAc and hexane extracts, and isolated compounds were evaluated by 2,2-diphenyl-1-picryl-hydrazyl-hydrate (DPPH) radical scavenging method as described by Mensor et al. in 2001 with slight modifications [23]. The test samples, initially dissolved in DMSO (SIGMA) were mixed with a $20 \mathrm{mg} / \mathrm{l}$ of 2,2-diphenyl-1-picryl-hydrazyl-hydrate $(\mathrm{DPPH})$ methanol solution, to give final concentrations of $10,50,100,500$ and $1000 \mu \mathrm{g} / \mathrm{ml}$. After $30 \mathrm{~min}$ at room temperature, the absorbance values were measured at $517 \mathrm{~nm}$ and converted into percentage of antioxidant activity as follows:

$\%$ Inhibition $=$ (Absorbance of control - Absorbance of test sample) $\times 100 /$ Absorbance of control

L-ascorbic acid was used as a standard control. The inhibition ratio was converted in probits. The probit values were plotted against the logarithmic values of concentrations of the test samples and a linear regression curve was established in order to determined the $\mathrm{IC}_{50}(\mu \mathrm{g} / \mathrm{ml})$ values, which is the amount of sample necessary to decrease by $50 \%$ the absorbance of DPPH. All the analyses were carried out in triplicate and the results were expressed as the mean \pm standard deviation (SD) and compared using Waller-Duncan test. A value of $p<0.05$ was considered statistically significant.

\section{Acknowledgements}

Dr. Tatsimo NSJ is grateful to AUF (Agence Universitaire de la Francophonie) for ten months travel grant to Hungary at the Department of Pharmacognosy, University of Szeged. We thank Mrs Tsobou and Koyeu (Plant Biology Department, University of Dschang) for the collection of the plant.

\section{Author details}

'Department of Chemistry, Higher Teachers' Training College, University of Maroua, P.O. Box 55, Maroua, Cameroon. 'Department of Biochemistry, Faculty of Science, University of Dschang, P.O. Box 67, Dschang, Cameroon. ${ }^{3}$ Department of Chemistry, Faculty of Science, University of Burundi, P.O. Box 2700, Bujumbura, Burundi. ${ }^{4}$ Department of Pharmacognosy, University of Szeged, Eötvös u. 6, H-6720 Szeged, Hungary. ${ }^{5}$ Department of Chemistry, University of Dschang, PO Box 67, Dschang, Cameroon.

\section{Authors' contributions}

JSNT designated the study, did the isolation and structure elucidation part with the help of DC, under the supervision of PT and JH. PF measured the NMR data of all the isolates. JDT and JRK did the biological part and participated in the preparation of the manuscript. LH helped in plant selection, study designation, manuscript writing and editing. All authors read and approved the final manuscript

\section{Competing interests}

The authors declare that they have no competing interests.

Received: 1 December 2011 Accepted: 20 March 2012

Published: 20 March 2012
2. Akinpelu DA: Antimicrobial activity of Bryophyllum pinnatum leaves. Fitoterapia 2000, 71:193-194.

3. Ojewole JAO: Antinociceptive, anti-inflammatory and antidiabetic effects of Bryophyllum pinnatum (Crassulaceae) leaf aqueous extract. J Ethnopharmacol 2005, 99:13-19.

4. Yemitan OK, Salahdeen HM: Neurosedative and muscle relaxant activities of aqueous extract of Bryophyllum pinnatum. Fitoterapia 2005, 76:187-193.

5. Yamagishi T, Yan X-Z, Wu R-Y, McPhail DR, McPhail AT, Lee K-H: Structure and stereochemistry of bryophyllin- $\mathrm{A}$, a novel potent cytotoxic bufadienolide orthoacetate from Bryophyllum pinnatum. Chem Pharm Bull 1988, 36:1615-1617.

6. Muzitano MF, Tinoco LW, Guette C, Kaiser CR, Rossi-Bergmann B, Costa SS: The antileishmanial activity assessment of unusual flavonoids from Kalanchoe pinnata. Phytochemistry 2006, 67:2071-2077.

7. Pal S, Chaudhuri AKN: Studies on the anti-ulcer activity of a Bryophyllum pinnatu leaf extract in experimental animals. J Ethnopharmacol 1991, 33:97-102.

8. Yadav NP, Dixit VK: Hepatoprotective activity of leaves of Kalanchoe pinnata Pers. J Ethnopharmacol 2003, 86:197-202.

9. Nakano K, Takatani M, Tomimatsu T, Nohara T: Four kaempferol glycosides from leaves of Cinnamomum sieboldii. Phytochemistry 1983, 22:2831-2833.

10. Pérez-Castorena A-L, Castro A, Romo De Vivar A: A dirhamnopyranoside from Psacalium megaphyllum. Phytochemistry 1997, 46:1297-1299.

11. Mizuno M, Linuma M, Tanaka T, Yamamoto H: Sutchuenoside A: a new kaempferol glycoside from the aerial parts of Epimedium sutchuenense. J Nat Prod 1991, 54:1427-1429.

12. Iñigo RPA, De Iglesias DIA, Catalan CAN: Kaempferol 3-a-Dglucopyranoside-7-a-L-rhamnopyranoside from Erythroxylon cuneifolium. Phytochemistry 1988, 27:1230-1231.

13. Tamokou JD, Tala FM, Wabo KH, Tane P: Antimicrobial activities of methanol extract and compounds from stem bark of Vismia rubescens. J Ethnopharmacol 2009, 124:571-575.

14. Hall CA, Cupett SL: Structure activities of natural antioxidants. In Antioxidant Methodology In Vitro Concepts. Edited by: Hudson BJL. London: Elsevier Applied Science; 1997:1-18.

15. Pietta $P$, Sionetti $P$, Mauri $P$ : Antioxidant activity of selected medicinal plants. J Agric Food Chem 1998, 46:4487-4490.

16. Cowan MM: Plant products as antimicrobial agents. Clin Microbiol Rev 1999, 12:564-582.

17. Tamokou JD, Kuiate JR, Tene M, Nwemeguela KTJ, Tane P: The Antimicrobial activities of extract and compounds isolated from Brillantaisia lamium. Iran J Med Sci 2011, 36:24-31.

18. Mohammad AH, Shigefumi M, Kotaro M, Hiroshi K, Eisuke S, Kazunori T, Takayoshi T, Shigera K: In vitro and in vivo activities of SCH5659 against Cryptococcus neoformans. J Antimicrob Chemother 1999, 44:827-829.

19. Paula CR, Krebs VL, Auler ME, Ruiz LS, Matsumoto FE, Silva EH, Diniz EM, Vaz FA: Nosocomial infection in newborns by Pichia anomala in a Brazilian intensive care unit. Med Mycol 2006, 44:479-484.

20. Kao AS, Brandt ME, Pruitt WR, Conn LA, Perkins BA, Stephens DS, Baughman WS, Reingold AL, Rothrock GA, Pfaller MA, Pinner RW, Hajjeh RA: The epidemiology of candidemia in two United States cities: results of a population based active surveillance. Clin Infect Dis 1999, 29:1164-1170.

21. Sarker SD, Latif Z, Gray Al: In Natural Products Isolation. Volume 2.. 2 edition. Totowa: Humana press; 2006

22. Nyaa TBL, Tapondjou AL, Barboni L, Tamokou JD, Kuiate JR, Tane P, Park HJ: NMR Assignment and antimicrobial/antioxidant activities of 1hydroxyeuscaphic acid from the seeds of Butyrospermum parkii. Nat Prod Sci 2009, 15:76-82

23. Mensor LL, Menezes FS, Leitao GG, Reis AS, Dos Santos TC, Coube CS, Leitao SG: Screening of Brazilian plant extracts for antioxidant activity by the use of DPPH free radical method. Phytother Res 2001, 15:127-130.

doi:10.1186/1756-0500-5-158

Cite this article as: Tatsimo et al:: Antimicrobial and antioxidant activity of kaempferol rhamnoside derivatives from Bryophyllum pinnatum. BMC Research Notes 2012 5:158.

\section{References}

1. Siddiqui S, Faizi S, Siddiqui BS, Sultana N: Triterpenoids and phenanthrenes from leaves of Bryophyllum pinnatum. Phytochemistry 1989, 28:2433-2438. 